\title{
Analysis of Draft Genome Sequence of Pseudomonas sp. QTF5 Reveals Its Benzoic Acid Degradation Ability and Heavy Metal Tolerance
}

\author{
Yang Li, ${ }^{1}$ Yi Ren, ${ }^{2}$ and Nan Jiang ${ }^{3}$ \\ ${ }^{1}$ Tianjin Institute of Industrial Biotechnology, Chinese Academy of Sciences, Tianjin, China \\ ${ }^{2}$ Shanghai Majorbio Bio-Pharm Biotechnology Co., Ltd, Shanghai, China \\ ${ }^{3}$ Institute of Applied Ecology, Chinese Academy of Sciences, Shenyang, China \\ Correspondence should be addressed to Nan Jiang; jiangnan@iae.ac.cn
}

Received 16 June 2017; Revised 4 October 2017; Accepted 1 November 2017; Published 15 November 2017

Academic Editor: Carla Renata Arciola

Copyright (C) 2017 Yang Li et al. This is an open access article distributed under the Creative Commons Attribution License, which permits unrestricted use, distribution, and reproduction in any medium, provided the original work is properly cited.

Pseudomonas sp. QTF5 was isolated from the continuous permafrost near the bitumen layers in the Qiangtang basin of QinghaiTibetan Plateau in China (5,111 $\mathrm{m}$ above sea level). It is psychrotolerant and highly and widely tolerant to heavy metals and has the ability to metabolize benzoic acid and salicylic acid. To gain insight into the genetic basis for its adaptation, we performed whole genome sequencing and analyzed the resistant genes and metabolic pathways. Based on 120 published and annotated genomes representing 31 species in the genus Pseudomonas, in silico genomic DNA-DNA hybridization $(<54 \%)$ and average nucleotide identity calculation $(<94 \%)$ revealed that QTF5 is closest to Pseudomonas lini and should be classified into a novel species. This study provides the genetic basis to identify the genes linked to its specific mechanisms for adaptation to extreme environment and application of this microorganism in environmental conservation.

\section{Introduction}

The Qiangtang basin is a region of continuous permafrost located in the Qinghai-Tibetan Plateau of China. It is an extreme environment with low temperatures, high UV radiation, and few nutrients. It is the largest petroleum-bearing basin in the plateau [1]. Our previous study [2] investigated the microbial composition and diversity of this area and found that Proteobacteria was the second largest phylum (following Actinobacteria), ranging from 18.7 to $20.43 \%$. The dominant class was Gammaproteobacteria, to which the genus Pseudomonas belongs.

Pseudomonas is aerobic and metabolically diverse, allowing it to occupy a wide range of niches [3]. Many species in the Pseudomonas genus are known for their resistance and survival in the presence of several organic and inorganic pollutants [4], including heavy metals [5], cyanide [6], normal hydrocarbons, and aromatic compounds [7]. Furthermore, certain species of Pseudomonas have been used for biocontrol [8] or bioremediation [9].
Pseudomonas sp. QTF5 was isolated from the soil sample near bitumen, which is the impermeable rock formation of petroleum [10]. It was chosen for whole genome sequencing because it is psychrotolerant and highly and widely tolerant to heavy metals and has the ability to metabolize benzoic acid and salicylic acid. Here, we present a summary of the classification and characteristics of QTF5, together with a description of the draft genome sequence and annotation. It is identified based on the phylogenetic placement of its $16 \mathrm{~S}$ rDNA sequence as well as pairwise digital DNA-DNA hybridization $(\mathrm{dDDH})$ values and average nucleotide identity (ANI).

\section{Materials and Methods}

2.1. Strain Isolation and Selection. Frozen soil was collected from the continuous permafrost beside the bitumen at 5,111 $\mathrm{m}$ above sea level in the Qiangtang basin [2]. Bacteria were originally isolated on PYGV agar medium at $15^{\circ} \mathrm{C}$. Pseudomonas sp. strain QTF5 was selected on the basis of its heavy 
metal resistance and benzoic acid degrading ability using a modified method described by Jebeli et al. [12]. Cells of strain QTF5 were examined in a HT7700 Transmission electron microscope (Hitachi, Tokyo, Japan) and a SU8010 scanning electron microscope (Hitachi, Tokyo, Japan). This strain was deposited in China General Microbiological Culture Collection Center (CGMCC) under accession number 1.15161.

2.2. Whole Genome Sequencing, Assembly, and Annotation. Cells of strain QTF5 were harvested from LB broth following overnight incubation at $30^{\circ} \mathrm{C}$ with shaking at $180 \mathrm{rpm}$. Genomic DNA was extracted using Genomic DNA Purification Kit (Fermentas, USA) according to the manufacturer's instruction. The genome of strain QTF5 was sequenced using the Illumina HiSeq 2000 and Miseq platforms. Two libraries of $400 \mathrm{bp}$ and $600 \mathrm{bp}$ insert size were generated and sequenced by $2 \times 100 \mathrm{bp}$ and $2 \times 300 \mathrm{bp}$ paired-end runs. A total of $2.4 \mathrm{~Gb}$ high quality data (15,971,017 reads) were assembled with the SOAP de novo assembler (v2.04) [13], providing approximately 410 -fold coverage. The coding sequences (CDSs) were predicted using Glimmer 3.0 [14] and their function was annotated through comparisons with databases of NR [15], COG [16], and KEGG [17]. The quality score of assembled sequences, rRNAs, tRNAs, and essential genes was calculated according to the algorithm described by Land et al. [18]. The quality score of genome sequences was assigned based on a combination of contigs and nonstandard bases. The rRNA score was calculated based on the length of predicted 5S, 16S, and 23S rRNAs. The tRNA score was based on predicted tRNAs, at least one of which codes for each of the 20 standard amino acids. A neighbor joining phylogenetic tree was constructed based on 16s rDNA sequences of QTF5 and other published representative strains of 19 species in genus Pseudomonas, with Azomonas as an outgroup. The tree uses the Jukes-Cantor corrected distance model to construct a distance matrix. Bootstrap values above $30 \%$, based on 1,000 replications, are shown at the branching points. GenBank accession number for each strain is shown in parenthesis.

2.3. Genome Wide Comparative Analysis. In order to further resolve the taxonomy of the new isolate, comparative genomic analysis was used to compare QTF5 with 120 genomes that represent 31 species across the genus Pseudomonas (Table S1 in Supplementary Material available online at https://doi.org/10.1155/2017/4565960). ANI was computed from protein coding genes of the genomes with the Jspecies program using default parameters [19]. $\mathrm{dDDH}$ values and their confidence intervals were determined using Genome-to-Genome Distance Calculator (GGDC 2.1 http://ggdc.dsmz.de) under recommended settings [20].

\subsection{Assessment of Heavy Metals Resistance and Benzoic Acid} Degradation. The level of resistance was determined for heavy metals in their salt forms according to a Maximum Inhibitory Concentration (MIC) method described previously [12]. The salts used were as follows: $\mathrm{ZnSO}_{4}(\mathrm{Zn})$, $\mathrm{Pb}\left(\mathrm{NO}_{3}\right)_{2}(\mathrm{~Pb}), \mathrm{CuSO}_{4}(\mathrm{Cu}), \mathrm{MnCl}_{2}(\mathrm{Mn}), \mathrm{CoCl}_{2}(\mathrm{Co})$, $\mathrm{NiSO}_{4}(\mathrm{Ni}), \mathrm{K}_{2} \mathrm{Cr}_{2} \mathrm{O}_{7}(\mathrm{Cr})$, and $\mathrm{HgCl}_{2}(\mathrm{Hg})$. To investigate the degradation ability of benzoic acid and its analogs, cultures were harvested after $4 \mathrm{~h}$ to obtain log phage cells. Washed cells were suspended in basic inorganic medium and then diluted to a concentration of $5.0 \times 10^{6}$ cells $/ \mathrm{ml} .200 \mu \mathrm{l}$ of the cell suspension (i.e., $10^{6}$ cells) was added to three individual wells of a microtiter plate containing $100 \mu \mathrm{l}$ of water, sodium benzoate (final concentration: $0.03 \%$ ) or salicylic acid (final concentration: $0.18 \%$ ), respectively. Individual wells in the same plate containing $200 \mu \mathrm{l}$ basic inorganic medium and $100 \mu \mathrm{l}$ one were used as the controls. Each treatment was repeated 4 times. The plates were incubated at $30^{\circ} \mathrm{C}$ with shaking for 3 days and then centrifuged at $4000 \mathrm{rpm}$ for 10 mins. The absorption spectrum of supernatant in each well was measured in an automated spectrophotometer SpectraMax $^{\circledR}$ M5 (Molecular Devices, LLC, Sunnyvale, California) [21].

2.5. Nucleotide Sequence Accession Number. The genome sequenced as part of this study has been deposited at GenBank under accession number AZRW00000000. The version described here represents an improved assembly and is the second version AZRW00000000.2.

\section{Results and Discussion}

3.1. General Feature of Pseudomonas sp. Strain QTF5. Strain QTF5 was isolated from frozen soil cultivated on PYGV medium at $15^{\circ} \mathrm{C}$. It is Gram-negative, nonmotile, and rodshaped measuring $0.5 \mu \mathrm{m}$ in diameter and $1.5 \mu \mathrm{m}$ in length (Figure 1). When incubated with fresh nutrient medium, QTF5 forms organized lumps on the agar surface, leading to the growth of dry opaque, pale orange, concentrically ringed colonies within 2 days. It could grow at a broad temperature range from 10 to $42^{\circ} \mathrm{C}$, with an optimum at $30^{\circ} \mathrm{C}$, at $\mathrm{pH}$ 5.6-8.0 (optimum at $\mathrm{pH}$ 6.6-7.0).

3.2. Physiological Characteristics of Strain QTF5. Tolerance of strain QTF5 to a wide range of heavy metals was assessed using MIC tests under optimal growth condition. Strain QTF5 is resistant to with MICs up to $32.0 \mathrm{mM}(\mathrm{Zn}), 12.8 \mathrm{mM}$ $(\mathrm{Pb}), 6.4 \mathrm{mM}(\mathrm{Cu}), 4.0 \mathrm{mM}(\mathrm{Mn}), 3.2 \mathrm{mM}(\mathrm{Co}), 3.2 \mathrm{mM}(\mathrm{Ni})$, $1.6 \mathrm{mM}(\mathrm{Cr})$, and $0.01 \mathrm{mM}(\mathrm{Hg})$, respectively. The highest MICs of other heavy metal resistant Pseudomonas strains described previously are lower than QTF5, or some strains are only resistant to one or several of these heavy metals [22-25]. For example, P. aeruginosa J007 and PAO1 are only resistant to three heavy metals. Specifically, the MICs of J007 were determined to be of $3 \mathrm{mM}(\mathrm{Cu}), 2 \mathrm{mM}(\mathrm{Cd})$, and $6 \mathrm{mM}$ $(\mathrm{Zn})$, and those of PAO1 were $2 \mathrm{mM}(\mathrm{Cu}), 0.125 \mathrm{mM}(\mathrm{Pb})$, and $8 \mathrm{mM}(\mathrm{Zn})$. Although $P$. aeruginosa CCTCC AB93066 is resistant to a wider range of heavy metals, the MICs of most heavy metals are much lower than QTF5, accounting for $0.97 \mathrm{mM}(\mathrm{Pb}), 1.57 \mathrm{mM}(\mathrm{Cu}), 0.83 \mathrm{mM}(\mathrm{Co})$, and $1.70 \mathrm{mM}$ (Ni). Compared with those reported strains, QTF5 has a much broader resistant spectrum and relatively higher tolerant level.

Moreover, strain QTF5 is able to utilize benzoic acid as the sole carbon and energy source for growth in basic medium. The degradation of benzoic acid involve several 


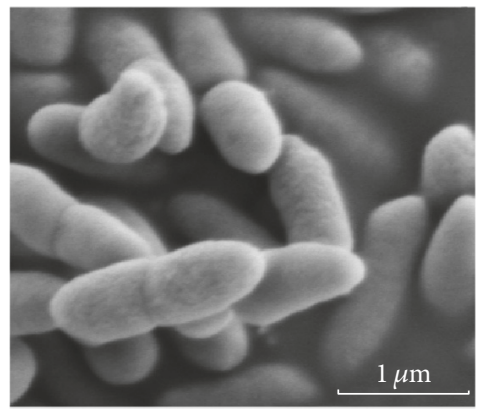

(a)

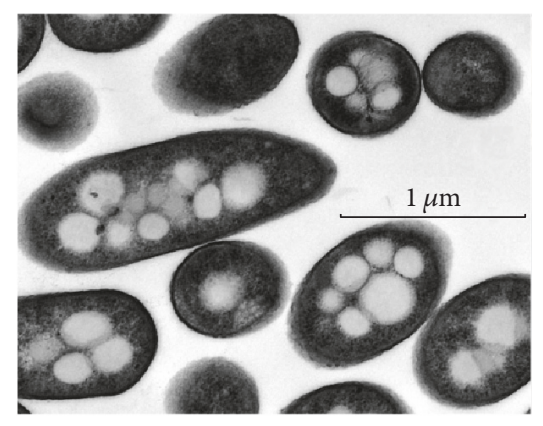

(b)

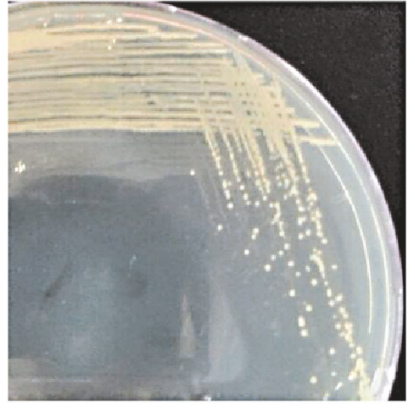

(c)

FIgURE 1: Characteristic images of Pseudomonas sp. QTF5. (a) Scanning electron microscopy image; (b) transmission electron microscopy image; (c) image of colonies on agar plate.

oxidation steps and the products cause increase of peak height in absorption spectra [26]. QTF5 can significantly change the absorption spectra (Figure 2), especially in the characteristic wavelength of benzoic acid $(230 \mathrm{nM})$ and salicylic acid ( $235 \mathrm{nM}, 305 \mathrm{nM})$ as reported previously [26-29]. Specifically, after adding the strain QTF5, $\mathrm{OD}_{230}$ significantly decreased from 3.14 to 2.75 in the wells with benzoic acid $(p<0.05)$, and $\mathrm{OD}_{235}$ significantly decreased from 3.01 to 2.90 and $\mathrm{OD}_{305}$ from 2.58 to 2.43 in the wells with salicylic acid $(p<0.05)$.

3.3. Genome Assembly and Gene Prediction. The draft genome consists of 90 scaffolds, which are composed of 101 contigs. The N50 length is $129 \mathrm{~kb}$ and the largest contig approximately $293 \mathrm{~kb}$. The quality score of assembled sequences, rRNAs, tRNAs, and essential genes are 0.87, 0.9, 0.9 , and 0.99 , respectively. The final quality score of the draft genome is 0.929 . The genome is composed of a circular chromosome without any extrachromosomal elements. The genome size was approximately $6,019,946$ bp with a $\mathrm{G}+\mathrm{C}$ content of $58.71 \%$ (Table 1). A total of 5,589 genes were predicted, 5,524 of which are protein coding genes, and 65 are RNA genes. 4,450 (79.74\%) of the protein coding genes were assigned to a putative function with the remaining annotated as hypothetical proteins or proteins of unknown functions.

3.4. Functional Annotation and Analysis. According to the KO assignment and KEGG pathway mapping, 2,849 (51.57\%) protein coding genes of strain QTF5 could be assigned to 112 metabolic pathways. Metabolic pathways consist of the most abundant gene set $(n=778,14.08 \%$ of total protein coding genes), followed by biosynthesis of secondary metabolites (347, 6.28\%), microbial metabolism in diverse environments (256, 4.63\%), and two-component system (170, 3.08\%). Using COG function assignment, 4,848 of protein coding genes could be classified into 22 COG categories. The properties and the statistics of the genome are summarized in Table 2. The most abundant category of metabolism, information storage and processing, and cellular processes and signaling are related to amino acid transport and metabolism (488, $8.83 \%)$, transcription $(414,7.49 \%)$, and signal transduction mechanisms (371, 6.72\%).
TABLE 1: Genome statistics.

\begin{tabular}{lcc}
\hline Attribute & Value & \% of total \\
\hline Genome size (bp) & $6,019,946$ & 100 \\
Coding region (bp) & $5,167,653$ & 85.84 \\
G + C content (bp) & $3,534,328$ & 58.71 \\
RNA genes & 65 & 1.163 \\
Protein-coding genes & 5,524 & 85.69 \\
Genes with function prediction & 4,405 & 79.74 \\
Genes assigned to COGs & 4,848 & 87.76 \\
Genes assigned to TIGRfam domains & 1,561 & 28.26 \\
Genes assigned to Pfam domains & 2,546 & 46.09 \\
Genes with signal peptides & 521 & 9.432 \\
Genes with transmembrane helices & 1213 & 21.96 \\
\hline
\end{tabular}

${ }^{*}$ The total is based on either the size of the genome in base pairs or the total number of protein coding genes in the annotated genome.

3.5. Taxonomical Classification. The phylogenetic position of genus Pseudomonas is in the Pseudomonadaceae, a very diverse family within the order Pseudomonadales, the phylum Proteobacteria. The closest related genera are Azomonas and Azotobacter [30, 31]. A phylogenetic tree of $16 \mathrm{~S}$ rDNA sequences reveals that $P$. lini [32] TGL-Y1 (GenBank: KF704098.1) and Pseudomonas brassicacearum subsp. brassicacearum [33] NFM421 (GenBank: CP002585.1) are the closest phylogenetic neighbors of QTF5 (Figure 3). The former stain was isolated, like QTF5, from Qinghai-Tibet Plateau and described as a crude oil degrading bacterium. In silico GGDC and ANI showed $54.1 \%$ and $94.01 \%$ identity to the closest relative, $P$. lini, respectively. The detailed results are shown in Table S1.

Genomic taxonomy can be studied through various parameters including average nucleotide identity and Genome BLAST Distance Phylogeny [20, 34]. Depending on the methods used for ANI calculation or the nature of bacterial genome sequences, 95 or $96.5 \%$ ANI value $[35,36]$ corresponds to the classical 70\% DNA-DNA relatedness cutoff value [37] for strains of the same species. The highest $\mathrm{dDDH}$ and ANI value between QTF5 and reference strain is far lower than the cutoff value, confirming that QTF5 belongs to a novel species within genus Pseudomonas. 


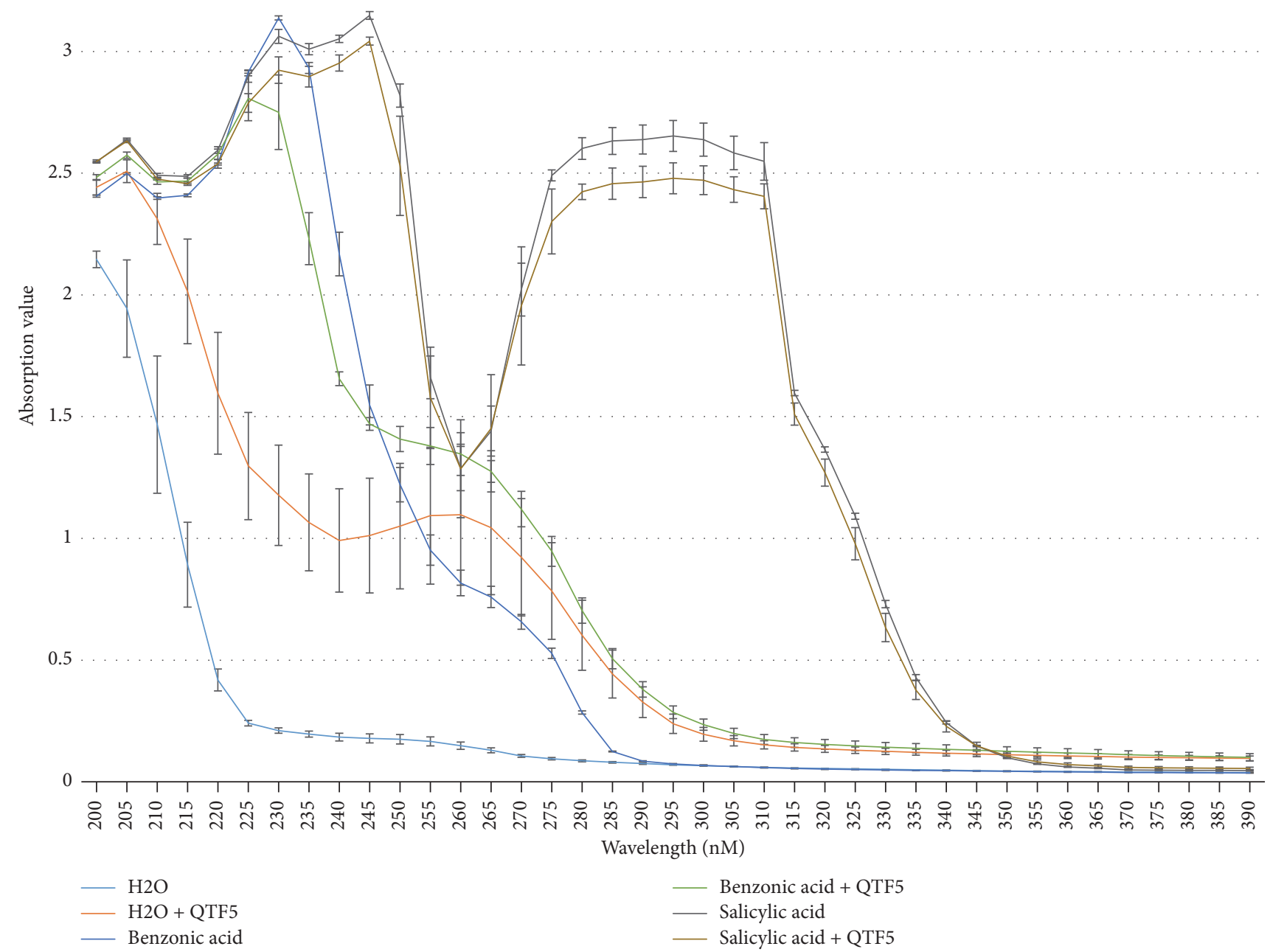

FIgURE 2: UV spectrum demonstrates the degradation of benzoic acid and salicylic acid by strain QTF5. The absorption value for each wavelength is the mean value of four replicated trials. The error bars indicate standard deviation.

3.6. Identification of Heavy Metal Resistance and Benzoic Acid Degradation Genes. All the genes involved in iron (III) transport system, iron complex transport system, and highaffinity zinc uptake system are present in this genome. Two copies of lead, cadmium, zinc, and mercury transporting ATPases, two copper resistance gene clusters, a heavy metal efflux system, nine heavy metal efflux and resistance genes, and two heavy metal responsive transcriptional regulators were identified, which may explain the high tolerance of this strain. Two gene clusters responsible for benzoate degradation, ben operon (204,627-209,577, AZRW02000002.1) and cat operon (209,854-213,318, AZRW02000002.1), were found on the genome (Figure 4), indicating the ability to metabolize benzoic acid. Seven cold-shock proteins were found in this genome including $\operatorname{csp} A, \operatorname{csp} C$, and $\operatorname{csp} D$. The recombination related genes $\operatorname{rec} A, \operatorname{rec} F, \operatorname{rec} G, \operatorname{rec} N, \operatorname{rec} O, \operatorname{rec} Q, \operatorname{rad} A, \operatorname{rad} C$, and single-stranded-DNA-specific exonuclease gene recJ, which play a critical role in DNA damage repair, were also found. The cold-shock, recombination repair of damaged
DNA, cyclic hydrocarbon degradation, and heavy metal efflux proteins are significant for this bacterium to survive the extreme environment in Tibetan plateau near bitumen, which has low temperature, high UV radiation, high heavy metal concentration, and low nutrition.

\section{Conclusions}

Genome analysis of a novel Pseudomonas sp. strain QTF5 revealed a high degree of consistency between genotypes and phenotypes, especially in heavy metal resistance, benzoic acid degradation, and psychrotolerant characteristic. Genome sequence of QTF5 provides insight into better understanding of the molecular mechanism of the genus Pseudomonas in extreme environment adaptation.

Oilfield wasteland or petroleum-contaminated soil is always associated with high concentration and broad spectrum of heavy metals and aromatic compounds, which are difficult to remove and degrade $[38,39]$. Heavy metal resistant bacteria can be efficient bioremediators of metals and 
TABLE 2: Number of genes associated with the 25 general COG functional categories.

\begin{tabular}{lccl}
\hline Code & Value & \% age & Description \\
\hline $\mathrm{A}$ & 1 & 0.02 & RNA processing and modification \\
$\mathrm{B}$ & 3 & 0.05 & Chromatin structure and dynamics \\
$\mathrm{C}$ & 278 & 5.03 & Energy production and conversion \\
$\mathrm{D}$ & 41 & 0.74 & Cell cycle control, cell division, chromosome partitioning \\
$\mathrm{E}$ & 488 & 8.83 & Amino acid transport and metabolism \\
$\mathrm{F}$ & 91 & 1.65 & Nucleotide transport and metabolism \\
$\mathrm{G}$ & 254 & 4.60 & Carbohydrate transport and metabolism \\
$\mathrm{H}$ & 197 & 3.57 & Coenzyme transport and metabolism \\
$\mathrm{I}$ & 189 & 3.42 & Lipid transport and metabolism \\
$\mathrm{J}$ & 182 & 3.29 & Translation, ribosomal structure and biogenesis \\
$\mathrm{K}$ & 414 & 7.49 & Transcription \\
$\mathrm{L}$ & 170 & 3.08 & Replication, recombination and repair \\
$\mathrm{M}$ & 289 & 5.23 & Cell wall/membrane/envelope biogenesis \\
$\mathrm{N}$ & 128 & 2.32 & Cell motility \\
$\mathrm{O}$ & 189 & 3.42 & Posttranslational modification, protein turnover, chaperones \\
$\mathrm{P}$ & 225 & Inorganic ion transport and metabolism \\
$\mathrm{Q}$ & 127 & 4.07 & Secondary metabolites biosynthesis, transport and catabolism \\
$\mathrm{R}$ & 568 & 2.30 & General function prediction only \\
$\mathrm{S}$ & 433 & 10.28 & Function unknown \\
$\mathrm{T}$ & 371 & Signal transduction mechanisms \\
$\mathrm{U}$ & 145 & 6.72 & Intracellular trafficking, secretion, and vesicular transport \\
$\mathrm{V}$ & 65 & 2.62 & Defense mechanisms \\
$\mathrm{W}$ & 0 & 1.18 & Extracellular structures \\
$\mathrm{Y}$ & 0 & - & Nuclear structure \\
$\mathrm{Z}$ & 0 & - & Cytoskeleton \\
$\mathrm{Z}$ & 676 & Not in COGs \\
\hline
\end{tabular}

${ }^{*}$ The total is based on the total number of protein coding genes in the annotated genome.

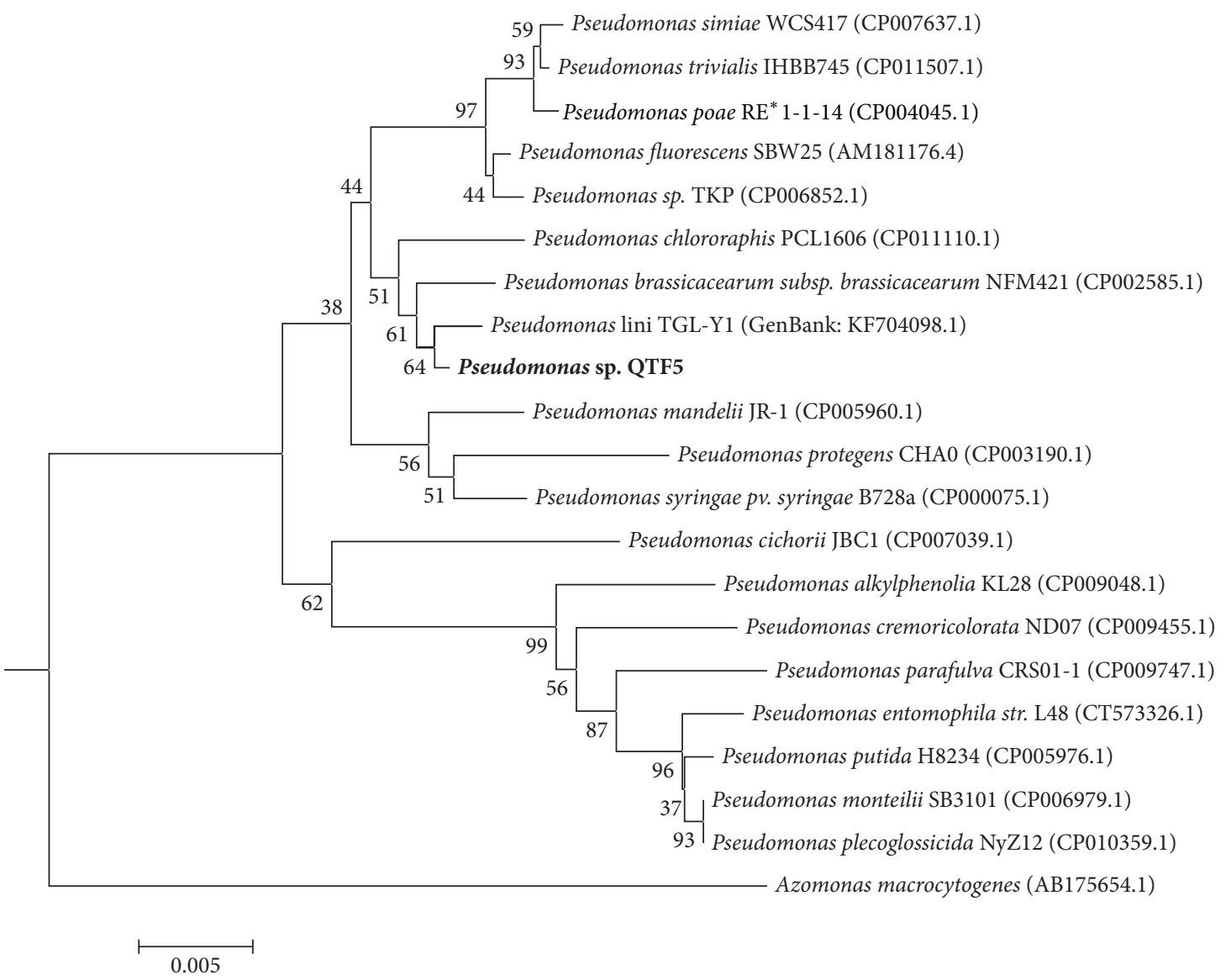

FIGURE 3: A neighbor joining phylogenetic tree of $16 \mathrm{~S}$ rDNA gene highlights the position of Pseudomonas sp. QTF5 relative to other strains within the genus Pseudomonas. GenBank accession number for each strain is shown in parenthesis. The tree uses the Jukes-Cantor corrected distance model to construct a distance matrix. Bootstrap values are shown at the branching points. Azomonas macrocytogenes [11] was used as an outgroup. 


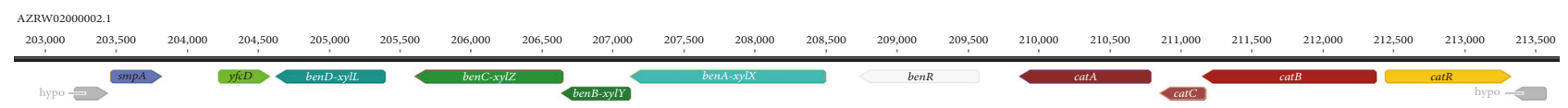

FIGURE 4: Genetic structure of benzoic acid degradation gene clusters, ben operon and cat operon, was detected in scaffold AZRW02000002.1 (scheme). The location and polarity of genes are shown with arrows. Hypo: hypothetical protein; smpA: membrane protein; $y f c D:$ NUDIX hydrolase; benD-xylL: 1,6-dihydroxycyclohexa-2,4-diene-1-carboxylate dehydrogenase; benC-xylZ: benzene 1,2-dioxygenase reductase component; benB-xylY: benzene 1,2-dioxygenase subunit beta; benA-xylX: benzene 1,2-dioxygenase subunit alpha; benR: ben operon regulatory protein; cat $A$ : catechol 1,2-dioxygenase; cat $C$ : muconolactone delta-isomerase; cat $B$ : muconate cycloisomerase; catR: cat operon regulatory protein.

may provide an alternative or additional method to conventional methods to remove them. Species of Pseudomonas have been proved to be highly effective in biosorption of metals [40] and QTF5 may be also used for enhanced remediation of contaminated environment. In addition, this strain has been shown to degrade benzoic acid, which is a major pollutant in petroleum-contaminated areas [39]. Strain QTF5 could potentially be used for biotechnological exploitation for perspective petroleum reservoir and bioremediation of environmental pollution.

\section{Conflicts of Interest}

The authors declare that they have no conflicts of interest.

\section{Authors' Contributions}

Yang Li and Yi Ren contributed equally to this work.

\section{Acknowledgments}

This work was supported by Natural Science Foundation of China (NSFC Grant nos. 41471217, 31100061, and 31300646) and the Science and Technology Planning Project of Tianjin (14ZCZDSY00058).

\section{References}

[1] J. He, J. Wang, X. Fu, C. Zheng, and Y. Chen, "Assessing the conditions favorable for the occurrence of gas hydrate in the Tuonamu area Qiangtang basin, Qinghai-Tibetan, China," Energy Conversion and Management, vol. 53, no. 1, pp. 11-18, 2012.

[2] N. Jiang, Y. Li, C. Zheng et al., "Characteristic microbial communities in the continuous permafrost beside the bitumen in Qinghai-Tibetan Plateau," Environmental Earth Sciences, vol. 74, no. 2, pp. 1343-1352, 2015.

[3] G. L. Winsor, D. K. W. Lam, L. Fleming et al., "Pseudomonas Genome Database: Improved comparative analysis and population genomics capability for Pseudomonas genomes," Nucleic Acids Research, vol. 39, no. 1, pp. D596-D600, 2011.

[4] S. Sharma, C. S. Sundaram, P. M. Luthra, Y. Singh, R. Sirdeshmukh, and W. N. Gade, "Role of proteins in resistance mechanism of Pseudomonas fluorescens against heavy metal induced stress with proteomics approach," Journal of Biotechnology, vol. 126, no. 3, pp. 374-382, 2006.

[5] C.-C. Chien, B.-C. Lin, and C.-H. Wu, "Biofilm formation and heavy metal resistance by an environmental Pseudomonas sp," Biochemical Engineering Journal, vol. 78, pp. 132-137, 2013.
[6] D. Wibberg, V. M. Luque-Almagro, M. I. Igeño et al., "Complete genome sequence of the cyanide-degrading bacterium Pseudomonas pseudoalcaligenes CECT5344," Journal of Biotechnology, vol. 175, no. 1, pp. 67-68, 2014.

[7] T. Krell, J. Lacal, M. E. Guazzaroni et al., "Responses of Pseudomonas putida to toxic aromatic carbon sources," Journal of Biotechnology, vol. 160, no. 1-2, pp. 25-32, 2012.

[8] P. Kupferschmied, M. Maurhofer, and C. Keel, "Promise for plant pest control: Root-associated pseudomonads with insecticidal activities," Frontiers in Plant Science, vol. 4, article 287, 2013.

[9] B. Z. Fathepure, "Recent studies in microbial degradation of petroleum hydrocarbons in hypersaline environments," Frontiers in Microbiology, vol. 5, article 173, 2014.

[10] H. Frumkin, J. Hess, and S. Vindigni, "Energy and public health: The challenge of peak petroleum," Public Health Reports, vol. 124, no. 1, pp. 5-19, 2009.

[11] P. B. New and Y. T. Tchan, "Azomonas macrocytogenes (ex Baillie, Hodgkiss, and Norris 1962, 118) nom. rev.," International Journal of Systematic Bacteriology, vol. 32, no. 3, pp. 381-382, 1982.

[12] M. A. Jebeli, A. Maleki, M. A. Amoozegar, E. Kalantar, H. Izanloo, and F. Gharibi, "Bacillus flexus strain As-12, a new arsenic transformer bacterium isolated from contaminated water resources," Chemosphere, vol. 169, pp. 636-641, 2017.

[13] R. Luo, B. Liu, Y. Xie et al., "SOAPdenovo2: an empirically improved memory-efficient short-read de novo assembler," Gigascience, vol. 1, no. 1, article 18, 2012.

[14] A. L. Delcher, K. A. Bratke, E. C. Powers, and S. L. Salzberg, "Identifying bacterial genes and endosymbiont DNA with Glimmer," Bioinformatics, vol. 23, no. 6, pp. 673-679, 2007.

[15] D. A. Benson, I. Karsch-Mizrachi, K. Clark, D. J. Lipman, J. Ostell, and E. W. Sayers, "GenBank," Nucleic Acids Research, vol. 40, no. D1, pp. D48-D53, 2012.

[16] C. von Mering, M. Huynen, D. Jaeggi, S. Schmidt, P. Bork, and B. Snel, "STRING: a database of predicted functional associations between proteins," Nucleic Acids Research, vol. 31, no. 1, pp. 258261, 2003.

[17] M. Kanehisa, S. Goto, Y. Sato, M. Kawashima, M. Furumichi, and M. Tanabe, "Data, information, knowledge and principle: back to metabolism in KEGG," Nucleic Acids Research, vol. 42, no. 1, pp. D199-D205, 2014.

[18] M. L. Land, D. Hyatt, S.-R. Jun et al., "Quality scores for 32,000 genomes," Standards in Genomic Sciences, vol. 9, no. 1, article 20, 2014.

[19] M. Richter and R. Rossello-Mora, "Shifting the genomic gold standard for the prokaryotic species definition," Proceedings of the National Acadamy of Sciences of the United States of America, vol. 106, no. 45, pp. 19126-19131, 2009. 
[20] J. P. Meier-Kolthoff, A. F. Auch, H.-P. Klenk, and M. Göker, "Genome sequence-based species delimitation with confidence intervals and improved distance functions," BMC Bioinformatics, vol. 14, article 60, 2013.

[21] C. Quintas, J. S. Leyva, R. Sotoca, M. C. Loureiro-Dias, and J. M. Peinado, "A model of the specific growth rate inhibition by weak acids in yeasts based on energy requirements," International Journal of Food Microbiology, vol. 100, no. 1-3, pp. 125-130, 2005.

[22] N. Hacioglu and M. Tosunoglu, "Determination of antimicrobial and heavy metal resistance profiles of some bacteria isolated from aquatic amphibian and reptile species," Environmental Modeling \& Assessment, vol. 186, no. 1, pp. 407-413, 2014.

[23] S. Choudhary and P. Sar, "Real-time PCR based analysis of metal resistance genes in metal resistant Pseudomonas aeruginosa strain J007," Journal of Basic Microbiology, vol. 56, no. 7, pp. 688697, 2016.

[24] C. Kang, P. Wu, Y. Li, B. Ruan, N. Zhu, and Z. Dang, "Estimates of heavy metal tolerance and chromium(VI) reducing ability of pseudomonas aeruginosa CCTCC AB93066: Chromium(VI) toxicity and environmental parameters optimization," World Journal of Microbiology and Biotechnology, vol. 30, no. 10, pp. 2733-2746, 2014.

[25] G. M. Teitzel and M. R. Parsek, "Heavy metal resistance of biofilm and planktonic Pseudomonas aeruginosa," Applied and Environmental Microbiology, vol. 69, no. 4, pp. 2313-2320, 2003.

[26] Y. Deng, K. Zhang, H. Chen et al., "Iron-catalyzed photochemical transformation of benzoic acid in atmospheric liquids: Product identification and reaction mechanisms," Atmospheric Environment, vol. 40, no. 20, pp. 3665-3676, 2006.

[27] J. Smith-Becker, E. Marois, E. J. Huguet, S. L. Midland, J. J. Sims, and N. T. Keen, "Accumulation of salicylic acid and 4hydroxybenzoic acid in phloem fluids of cucumber during systemic acquired resistance is preceded by a transient increase in phenylalanine ammonia-lyase activity in petioles and stems," Plant Physiology, vol. 116, no. 1, pp. 231-238, 1998.

[28] B. K. Paul and N. Guchhait, "Evidence for excited-state intramolecular proton transfer in 4-chlorosalicylic acid from combined experimental and computational studies: Quantum chemical treatment of the intramolecular hydrogen bonding interaction," Chemical Physics, vol. 403, pp. 94-104, 2012.

[29] L. Evangelisti, S. Tang, B. Velino, and W. Caminati, "Microwave spectrum of salicylic acid," Journal of Molecular Structure, vol. 921, no. 1-3, pp. 285-288, 2009.

[30] A. I. Özen and D. W. Ussery, "Defining the Pseudomonas Genus: Where Do We Draw the Line with Azotobacter?" Microbial Ecology, vol. 63, no. 2, pp. 239-248, 2012.

[31] R. Munoz, P. Yarza, W. Ludwig et al., "Release LTPs104 of the All-Species Living Tree," Systematic and Applied Microbiology, vol. 34, no. 3, pp. 169-170, 2011.

[32] S. Delorme, P. Lemanceau, R. Christen, T. Corberand, J.-M. Meyer, and L. Gardan, "Pseudomonas lini sp. nov., a novel species from bulk and rhizospheric soils," International Journal of Systematic and Evolutionary Microbiology, vol. 52, no. 2, pp. 513-523, 2002.

[33] E. P. Ivanova, R. Christen, C. Bizet et al., "Pseudomonas brassicacearum subsp. neoaurantiaca subsp. nov., orange-pigmented bacteria isolated from soil and the rhizosphere of agricultural plants," International Journal of Systematic and Evolutionary Microbiology, vol. 59, no. 10, pp. 2476-2481, 2009.

[34] K. T. Konstantinidis and J. M. Tiedje, "Genomic insights that advance the species definition for prokaryotes," Proceedings of the National Acadamy of Sciences of the United States of America, vol. 102, no. 7, pp. 2567-2572, 2005.

[35] M. Kim, H. Oh, S. Park, and J. Chun, "Towards a taxonomic coherence between average nucleotide identity and 16S rRNA gene sequence similarity for species demarcation of prokaryotes," International Journal of Systematic and Evolutionary Microbiology, vol. 64, no. Pt 2, pp. 346-351, 2014.

[36] N. J. Varghese, S. Mukherjee, N. Ivanova et al., "Microbial species delineation using whole genome sequences," Nucleic Acids Research, vol. 43, no. 14, pp. 6761-6771, 2015.

[37] Y. Liu, Q. Lai, M. Göker et al., "Genomic insights into the taxonomic status of the Bacillus cereus group," Scientific Reports, vol. 5, article 14082, 2015.

[38] S. Grujić, M. Ristić, and M. Laušević, "Heavy metals in petroleum-contaminated surface soils in Serbia," Annali di Chimica, vol. 94, no. 12, pp. 961-970, 2004.

[39] L. T. Nhi-Cong, A. Mikolasch, S. Awe, H. Sheikhany, H.P. Klenk, and F. Schauer, "Oxidation of aliphatic, branched chain, and aromatic hydrocarbons by nocardia cyriacigeorgica isolated from oil-polluted sand samples collected in the saudi arabian desert," Journal of Basic Microbiology, vol. 50, no. 3, pp. 241-253, 2010.

[40] T. Naz, M. D. Khan, I. Ahmed et al., "Biosorption of heavy metals by Pseudomonas species isolated from sugar industry," Toxicology \& Industrial Health, vol. 32, no. 9, pp. 1619-1627, 2016. 

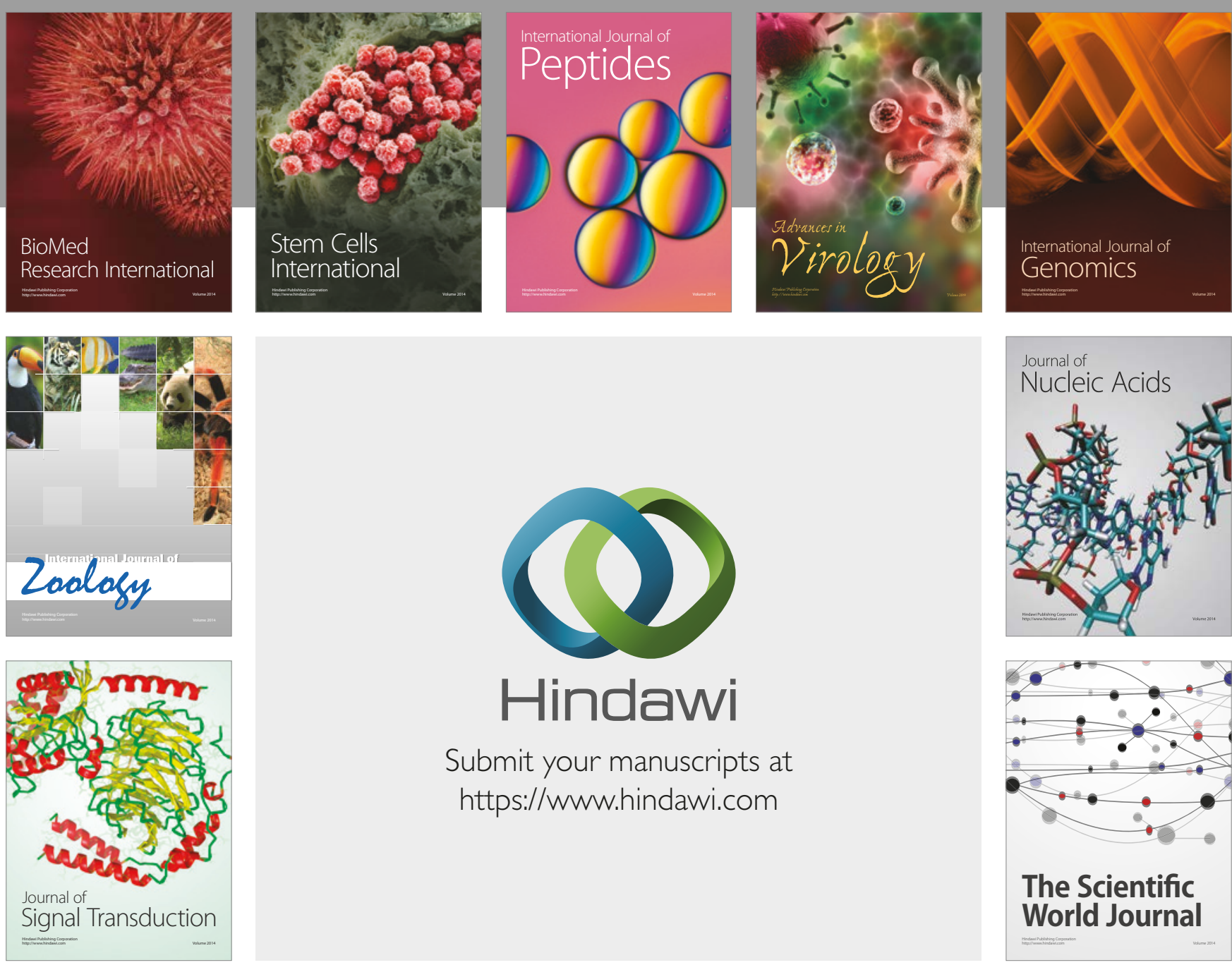

Submit your manuscripts at

https://www.hindawi.com
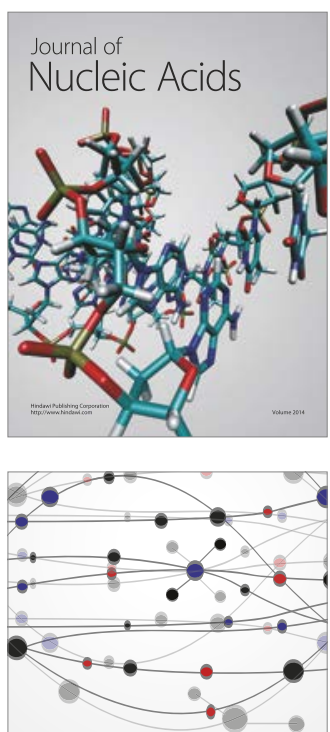

The Scientific World Journal

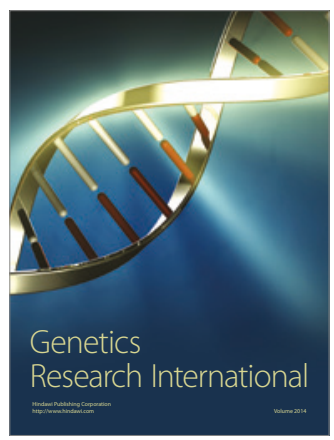

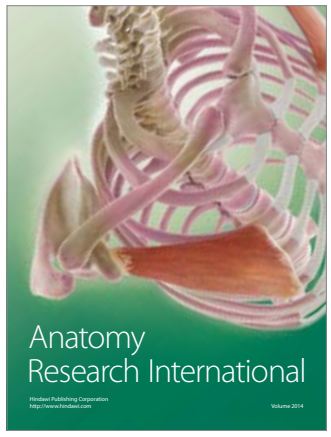

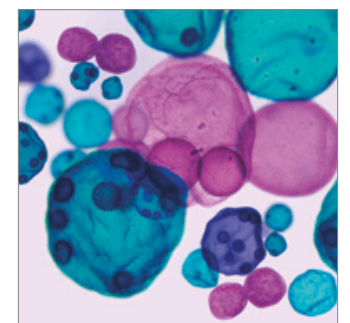

International Journal of Microbiology
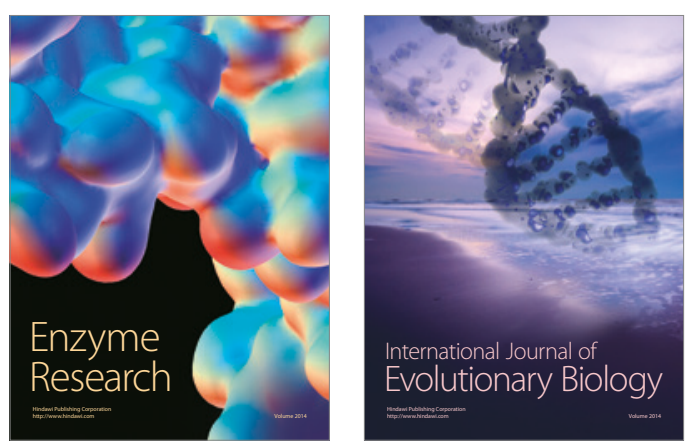
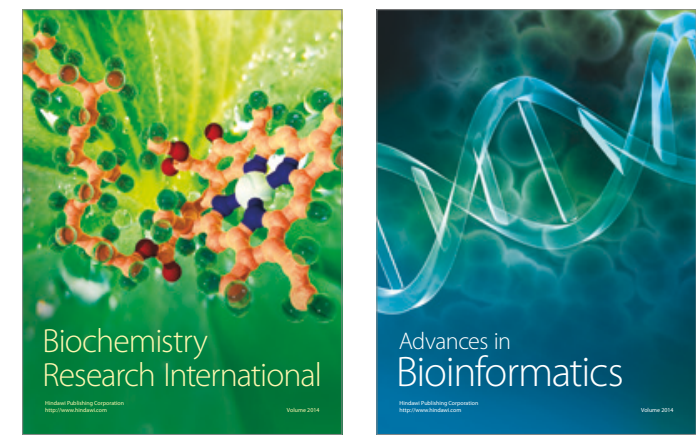

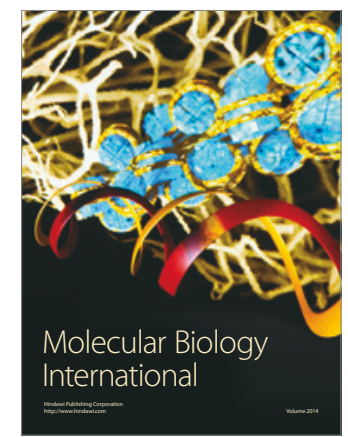

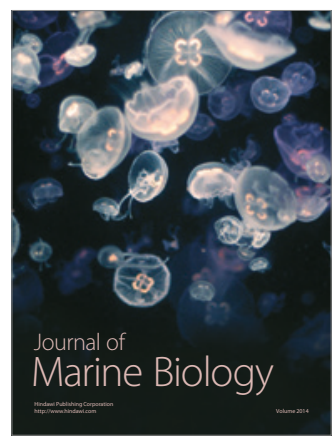

